\title{
A role for leptin in rheumatic diseases?
}

\section{G Palmer, C Gabay}

\section{Leptin may influence RA in opposing ways: enhance the expression of Th 1 cytokines or limit the inflammatory responses}

ep ptin is a peptide hormone that has an important role in the regulation of -body weight by inhibiting food intake and stimulating energy expenditure. Moreover, leptin exhibits a variety of other effects, including the regulation of endocrine function, reproduction, and immunity. ${ }^{12}$ Consistently, leptin deficient (ob/ob) mice and leptin receptor deficient $(\mathrm{db} / \mathrm{db})$ mice are not only severely obese but also display hormonal imbalances, abnormalities in thermoregulation, infertility, and evidence of immune and haematopoietic defects. The role of leptin in the modulation of the immune response and inflammation has lately received particular attention.

\section{LEPTIN AND IMMUNE RESPONSE}

It has long been known that ob/ob and $\mathrm{db} / \mathrm{db}$ mice have an altered immune response. $^{34}$ More recent studies have shown that the long isoform of the leptin receptor $(\mathrm{OB}-\mathrm{Rb})$ is expressed in $\mathrm{T}$ and $\mathrm{B}$ cells and indicated that leptin exerts direct effects on lymphocytes. ${ }^{5-7}$ Leptin was reported to stimulate the proliferation of $\mathrm{T}$ cells in vitro, to promote $\mathrm{T}$ helper (Th) 1 responses, and to protect $\mathrm{T}$ cells from corticosteroid induced apoptosis. ${ }^{5}$

Consistently, ob/ob and db/db mice have a marked reduction in the size and cellularity of the thymus and exhibit defective $\mathrm{T}$ cell mediated immunity. ${ }^{3}$ Furthermore, starvation and malnutrition, two conditions characterised by low leptin levels, are also associated with alterations of the immune response and thymic atrophy, which can be reversed by leptin administration. ${ }^{57}$ Despite strong evidence for the direct effects of leptin on $\mathrm{T}$ cells in vitro, the connection between leptin deficiency and immune defects in vivo is likely to be more complex. Ob/ob and $\mathrm{db} / \mathrm{db}$ mice indeed display multiple endocrine and metabolic modifications, including hypercorticosteronaemia and diabetes, which may indirectly affect the immune system. Similarly, leptin deficiency after starvation in rodents is linked to increased glucocorticoid levels, and decreased levels of thyroid and growth hormone, each of which may mediate immune suppression. ${ }^{8}$ Both the

direct and indirect effects of leptin are thus likely to account for the immune defects observed in leptin deficient animals. In humans, congenital leptin deficiency is associated with a decreased number of circulating CD4 $+\mathrm{T}$ cells, and impaired $\mathrm{T}$ cell proliferation and cytokine release, all of which can be reversed by the administration of recombinant leptin. ${ }^{9}$

Its abovementioned immunomodulatory and Thl promoting effects suggest that leptin may play a part in the regulation of autoimmune inflammatory conditions. Consistently, leptin deficient mice are protected from inflammation mediated by $\mathrm{T}$ and $\mathrm{B}$ cells in different disease models, including experimental autoimmune encephalomyelitis (EAE), type I diabetes, experimental colitis, and antigen induced arthritis (AIA). ${ }^{60^{10-12}} \mathrm{Ad}$ ministration of exogenous leptin restores the responsiveness of ob/ob mice to $\mathrm{T}$ cell-activating stimuli. ${ }^{10}$ In addition, in EAE, treatment with leptin after disease onset increases the severity of the symptoms. ${ }^{13}$ Similarly, in non-obese diabetic mice, leptin administration accelerates the autoimmune destruction of $\beta$ cells and increases interferon $\gamma$ production by peripheral T cells. ${ }^{11}$

\section{"Leptin may play a part in the regulation of autoimmune inflammatory conditions"}

AIA is a model of immune mediated joint inflammation induced by administration of methylated bovine serum albumin (mBSA) into the knees of immunised mice. The severity of arthritis in leptin and leptin receptor deficient mice was reduced in this model. ${ }^{6}$ The milder form of AIA seen in ob/ob and $\mathrm{db} / \mathrm{db}$ mice, as compared with their controls, was accompanied by decreased synovial levels of interleukin (IL) $1 \beta$ and tumour necrosis factor (TNF) $\alpha$, decreased proliferative response to antigen of lymph node cells in vitro, and a switch towards production of Th2 cytokines. ${ }^{6}$ Serum levels of all isotypes of anti-mBSA antibodies were significantly decreased in arthritic ob/ob mice as compared with controls. In AIA, leptin thus probably contributes to joint inflammation by regulating both humoral and cell mediated immune responses.

\section{LEPTIN AND INFLAMMATION}

The innate immune system has a major role in the regulation of leptin production. In experimental animal models, leptin levels are acutely increased by inflammatory and infectious stimuli, such as lipopolysaccharide (LPS), turpentine, and proinflammatory cytokines. ${ }^{14}{ }^{15}$ The increase in leptin production during infection and inflammation strongly suggests that leptin is part of the cytokine cascade, which orchestrates the innate immune response and host defence mechanisms. However, both pro- and antiinflammatory effects have been described for leptin according to the experimental model investigated.

In vitro, leptin stimulates both proand anti-inflammatory cytokine production in monocytes and macrophages..$^{16-19}$ Macrophages isolated from ob/ob mice show increased basal expression of IL6 and seem to be constitutively activated, implying that leptin may inhibit macrophage activation in vivo. ${ }^{20}$ However ob/ob mice also display impaired innate host response to bacterial pneumonia, indicating that here leptin plays an important part in the activation of host defence against infection. ${ }^{21}$ Finally, leptin deficient mice display an increased sensitivity to TNF $\alpha$ and LPS induced lethality, indicating that a functional leptin system confers protective antiinflammatory effects against these systemic proinflammatory stimuli. ${ }^{18} 22$

The intravenous injection of Staphylococcus aureus results in a severe form of septic arthritis in mice, which is associated with decreased circulating levels of leptin. In this model, treatment with leptin significantly decreased the severity of arthritis without interfering with the staphylococcal load in the joints. ${ }^{23}$ Preceding the effect on joint manifestations, serum levels of IL6 decreased in mice treated with leptin. In this model of septic arthritis, leptin thus reduced both the severity of joint manifestations and the inflammatory response. Similarly, we recently explored the role of leptin in zymosan induced arthritis (ZIA), a model of monoarticular arthritis which is not dependent on the adaptive immune response (Bernotiene $\mathrm{E}$ et al, unpublished data). In contrast with AIA, ZIA was not impaired in ob/ob and db/db mice. On the contrary, the resolution of joint swelling in ZIA was delayed in the absence of leptin or leptin signalling. The acute phase response, assessed by measuring circulating levels of IL6 and serum amyloid A, remained higher for a longer period of time in ob/ob mice than in control littermates. Furthermore, histological features of arthritis tended to be 
more severe at late time points in ob/ob mice. The delayed resolution of ZIA in $\mathrm{ob} / \mathrm{ob}$ and $\mathrm{db} / \mathrm{db}$ mice suggests that, in this model, leptin displays antiinflammatory properties. As previously observed with systemic proinflammatory stimuli, ${ }^{1822}$ leptin may thus also be involved in the control of local inflammatory events in the joint.

\section{A ROLE FOR LEPTIN IN HUMAN RHEUMATIC DISEASES?}

In patients with rheumatoid arthritis (RA) it was reported that fasting leads to an improvement of different clinical and biological measures of disease activity, which was associated with a marked decrease in serum leptin and a shift towards Th2 cytokine production. ${ }^{24}$ These features, resembling those seen during AIA in ob/ob mice, suggest that leptin may also influence the inflammatory mechanisms of arthritis in humans through the induction of Thl responses. However, the same investigators showed that after a seven day ketogenic diet in patients with RA, there were no significant changes in any clinical or biological measurements of disease activity, despite a significant decrease in serum leptin concentrations. ${ }^{25}$

\section{"A ketogenic diet reduces leptin concentrations but does not improve measures of disease activity"}

In this issue of the Annals, Bokarewa et al report increased plasma levels of leptin in 76 patients with RA as compared with healthy controls. ${ }^{26}$ The authors also observed that circulating plasma concentrations of leptin were significantly higher than leptin levels in matched synovial fluid samples and that the difference between plasma and synovial fluid was particularly pronounced in non-erosive arthritis. The authors concluded that intra-articular leptin may exert a protective effect against the destructive course of RA. Consistent with this hypothesis, these investigators previously observed that treatment with leptin decreases the severity of joint damage in an experimental model of septic arthritis. ${ }^{23}$ Unfortunately, several problems limit the interpretation of their results in patients with RA: (a) their study was cross sectional and thus, does not provide any information on the role of leptin on the course of the disease, particularly on the progression of joint damage; $(b)$ besides the measurement of $C$ reactive protein (CRP) levels, the authors did not give any indication about disease activity; (c) most importantly, the authors did not provide any information about the body mass index (BMI) of the subjects studied. This makes interpretation of the results difficult, because plasma leptin levels are strongly influenced by BMI and fat mass.

How do the results of Bokarewa et al compare with those of other studies? Two different groups showed that serum levels of leptin were not increased in patients with RA as compared with controls. In addition, they did not find any correlation between leptin levels and either clinical or biological signs of disease activity, whereas a positive correlation was seen between leptin and BMI or the percentage of body fat. ${ }^{27}{ }^{28}$ Another group reported lower plasma leptin levels in patients with RA than in controls. In patients with RA from this cohort, leptin did not correlate with BMI, CRP, total fat mass, or disease activity score. ${ }^{29}$ Leptin levels were also examined in other inflammatory rheumatic diseases. Forty one women with systemic lupus erythematosus (SLE) were compared with 23 healthy controls. After adjustment for BMI, patients with SLE had significantly higher serum levels of leptin than healthy subjects. However, there was no correlation between leptin levels and the Mexican SLE disease activity index (Mex-SLEDAI). ${ }^{30}$ Finally, in 35 patients with Behçet's syndrome, leptin levels were significantly higher than in healthy controls and correlated positively with disease activity. ${ }^{31}$

Taken together, the data of different clinical studies indicate that leptin levels cannot be used to assess the disease activity in RA and SLE. However, the results of Bokarewa et al suggest that leptin may influence the outcome of RA. Despite the presence of methodological problems in their study, this point is of interest because experimental models suggest that leptin may influence the disease process in two opposing ways, either by enhancing the expression of Thl cytokines or by limiting the inflammatory responses. Thus, longitudinal studies including patients with early RA are still needed to clarify the potential influence of leptin on disease outcome, and particularly the progression of joint damage. Likewise, it would certainly be worth performing similar studies in other immune mediated inflammatory rheumatic diseases.

\section{Ann Rheum Dis 2003;62:913-915}

\section{Authors' affiliations}

G Palmer, C Gabay, Division of

Rheumatology, University Hospital of Geneva and Department of Pathology, University of Geneva School of Medicine, Geneva,

Switzerland

Correspondence to: Professor C Gabay, Division of Rheumatology, University Hospital of Geneva, 26 avenue Beau-Séjour, 1211 Geneva 14, Switzerland; cem.gabay@hcuge.ch

\section{REFERENCES}

1 Ahima RS, Flier JS. Leptin. Annu Rev Physiol 2000;62:413-37.
2 Fantuzzi G, Faggioni R. Leptin in the regulation of immunity, inflammation, and hematopoiesis. J Leukoc Biol 2000;68:437-46.

3 Chandra RK. Cell-mediated immunity in genetically obese C57BL/6J (ob/ob) mice. Am J Clin Nutr 1980;33:13-16.

4 Fernandes G, Handwerger BS, Yunis EJ, Brown DM. Immune response in the mutant diabetic C57BL/Ks-db+ mouse. Discrepancies between in vitro and in vivo immunological assays. J Clin Invest 1978;61:243-50.

5 Lord GM, Matarese G, Howard JK, Baker RI, Bloom SR, Lechler RI. Leptin modulates the T-cell immune response and reverses starvation-induced immunosuppression. Nature 1998;394:897-901.

6 Busso N, So A, Chobaz-Peclat V, Morard C, Martinez-Soria, Talabot-Ayer D, et al. Leptin signaling deficiency impairs humoral and cellular immune responses and attenuates experimental arthritis. J Immunol 2002;168:875-82

7 Howard JK, Lor GM, Matarese G, Vendetti S, Ghatei MA, Ritter MA, et al. Leptin protects mice from starvation-induced lymphoid atrophy and increases thymic cellularity in ob/ob mice. J Clin Invest 1999; 104:1051-9.

8 Flier JS. Lowered leptin slims immune response. Nat Med 1998;4:1 124-5

9 Farooqi IS, Matarese G, Lord GM, Keogh $J M$, Lawrence $E$, Agwu C, et al. Beneficial effects of leptin on obesity, T cell hyporesponsiveness, and neuroendocrine/ metabolic dysfunction of human congenital leptin deficiency. J Clin Invest 2002;110:1093-103.

10 Matarese G, Di Giacomo A, Sanna V, Lord GM, Howard JK, Di Tuoro A, et al. Requirement for leptin in the induction and progression of autoimmune encephalomyelitis. $\mathrm{J}$ Immunol 2001;166:5909-16.

11 Matarese G, Sanna V, Lechler RI, Sarvetnick $\mathrm{N}$, Fontana S, Zappacosta S, et al. Leptin accelerates autoimmune diabetes in female NOD mice. Diabetes 2002;51:1356-61.

12 Siegmund B, Lehr HA, Fantuzzi G. Leptin: a pivotal mediator of intestinal inflammation in mice. Gastroenterology 2002; 122:201 1-25.

13 Matarese G, Sanna V, Di Giacomo A, Lord GM, Howard JK, Bloo SR, et al. Leptin potentiates experimental autoimmune encephalomyelitis in SJL female mice and confers susceptibility to males. Eur J Immunol 2001;31:1324-32

14 Sarraf $\mathbf{P}$, Frederich RC, Turner EM, Ma G Jaskowiak NT, Rivet DJ, et al. Multiple cytokines and acute inflammation raise mouse leptin levels: potential role in inflammatory anorexia. J Exp Med 1997;185:171-5.

15 Faggioni R, Fantuzzi G, Fuller J, Dinarello CA, Feingold KR, Grunfeld C. IL-1 beta mediates leptin induction during inflammation Am J Physiol 1998;274:R204-8.

16 Zarkesh-Esfahani H, Pockley G, Metcalfe RA, Bidlingmaier $M, W u Z, A j a m i$, et al. High-dose leptin activates human leukocytes via receptor expression on monocytes. J Immunol 2001;167:4593-9.

17 Loffreda S, Yang SQ, Lin HZ, Karp CL, Brengman ML, Wang DJ, et al. Leptin regulates proinflammatory immune responses. FASEB J 1998; 12:57-65.

18 Faggioni R, Fantuzzi G, Gabay C, Moser A, Dinarello CA, Feingold KR, et al. Leptin deficiency enhances sensitivity to endotoxin-induced lethality. Am J Physiol 1999;276:R136-42.

19 Gabay C, Dreyer M, Pellegrinelli N, Chicheportiche R, Meier CA. Leptin directly induces the secretion of interleukin 1 receptor antagonist in human monocytes. J Clin Endocrinol Metab 2001;86:783-91.

20 Lee FY, Li Y, Yang EK, Yang SQ, Lin HZ, Trush MA, et al. Phenotypic abnormalities in macrophages from leptin-deficient, obese mice. Am J Physiol 1999;276:C386-94

21 Mancuso P, Gottschalk A, Phare SM, Peters-Golden M, Lukacs NW, Huffnagl GB. Leptin-deficient mice exhibit impaired host defense in Gram-negative pneumonia. J Immunol 2002;168:4018-24. 
22 Takahashi N, Waelput W, Guisez Y. Leptin is an endogenous protective protein against the toxicity exerted by tumor necrosis factor. J Exp Med 1999; 189:207-12.

23 Hultgren $\mathbf{O H}$, Tarkowski A. Leptin in septic arthritis: decreased levels during infection and amelioration of disease activity upon its administration. Arthritis Res 2001;3:389-94.

24 Fraser DA, Thoen J, Reseland JE, Forre O, Kjeldsen-Kragh J. Decreased CD4+ lymphocyte activation and increased interleukin-4 production in peripheral blood of rheumatoid arthritis patients after acute starvation. Clin Rheumatol 1999;18:394401.

25 Fraser DA, Thoen J, Bondhus S, Haugen M, Reseland JE, Dioseland O, et al. Reduction in serum leptin and IGF-1 but preserved T-lymphocyte numbers and activation after a ketogenic diet in rheumatoid arthritis patients. Clin Exp Rheumatol 2000; 18:209-14.

26 Bokarewa M, Bokarew D, Hultgren O, Tarkowski A. Leptin consumption in the inflamed joints of patients with rheumatoid arthritis. Ann Rheum Dis 2003;62:952-6.

27 Anders HJ, Rihl M, Heufelder A, Loch O, Schattenkirchner $M$. Leptin serum levels are not correlated with disease activity in patients with rheumatoid arthritis. Metabolism 1999;48:745-8.

28 Nishiya K, Nishiyama M, Chang A, Shinto A, Hashimoto K. [Serum leptin levels in patients with rheumatoid arthritis are correlated with body mass index.] Rinsho Byori 2002; 50:524-7
29 Tokarczyk-Knapik A, Nowicki M, Wyroslak J. [The relation between plasma leptin concentration and body fat mass in patients with rheumatoid arthritis.] Pol Arch Med Wewn 2002;108:761-7.

30 Garcia-Gonzalez A, Gonzalez-Lopez L, Valera-Gonzalez IC, Cardona-Munoz EG, Salazar-Paramo M, Gonzalez-Ortiz M, et al. Serum leptin levels in women with systemic lupus erythematosus. Rheumatol Int 2002;22:138-41.

31 Evereklioglu $C$, Inaloz HS, Kirtak N, Doganay S, Bulbul M, Ozerol E, et al. Serum leptin concentration is increased in patients with Behçet's syndrome and is correlated with disease activity. Br J Dermatol 2002; 147:331-6.

\section{Get published within days of acceptance with ARD}

We are delighted to announce that the Annals of the Rheumatic Diseases is launching a "publish ahead of print" programme from February 2004. Selected papers will be fast tracked and published online months before they appear in the print journal.

Papers of major significance to the international rheumatology community will be published within days of acceptance. The published article will be the raw accepted manuscript; edited and typeset versions will also be published as soon as they are available.

In addition to being available on ARD Online, the publish ahead of print articles will be searchable through PubMed/Medline-establishing primacy for your work. They will be linked from the ARD Online home page.

$A R D^{\prime}$ s publish ahead of print programme is unique among the major rheumatology journals-to take advantage of this service submit your papers to the Annals of the Rheumatic Diseases using our online submission and review system Bench>Press (http://submit-ard.bmijournals.com). For further information contact ARD@bmigroup.com. 